DOI: 10.12731/2658-6649-2020-12-5-16-21

УДК 616.34-008.1/.7-009.1-053.2 (470.56)

\title{
АКТУАЛЬНЫЕ АСПЕКТЫ ЭТИОЛОГИИ И КЛИНИКИ СИНДРОМА РАЗДРАЖЕННОГО КИШЕЧНИКА У ДЕТЕЙ
}

\author{
Малеева Н.П., Кацова Г.Б.
}

Проблема синдрома раздраженного кишечника (СРК) является одной из самых актуальных в детской гастроэнтерологии. Цель исследования определить распространенность, этиологическую структуру, клинику СРК в зависимости от возраста. Обследовано 200 детей от 5 до 16 лет посетивших амбулаторный прием у гастроэнтеролога. Полученные результаты позволили сформировать дифференцированный подход к клинике в зависимости от этиологических факторов и возраста детей с СРК. Данное исследование позволяет проводить раннюю профилактику СРК, оптимизировать план обследование и рациональную терапию.

Ключевые слова: дети; синдром раздраженного кишечника; распространенность; этиология; клиника.

\section{CURRENT ASPECTS OF THE ETIOLOGY AND CLINIC OF IRRITABLE BOWEL SYNDROME IN CHILDREN}

\author{
Maleeva N.P., Katsova G.B.
}

The problem of irritable bowel syndrome (IBS) is one of the most urgent in pediatric gastroenterology. The aim of the study is to determine the prevalence, etiological structure, and clinic of IBS depending on age. We examined 200 children from 5 to 16 years old who attended an outpatient appointment with a gastroenterologist. The results obtained made it possible to form a differentiated approach to the clinic depending on etiological factors and the age of children with IBS. This study allows for early prevention of IBS, optimization of the examination plan and rational therapy.

Keywords: children; irritable bowel syndrome; prevalence; etiology; clinic. 
Нарушением моторной функции сопровождается большинство заболеваний желудочно-кишечного тракта как верхних, так и нижних его отделов. Нарушение моторики, связанное с патологическим процессом, носит органический характер. В других случаях моторика является следствием нарушения регуляции со стороны нервной и эндокринной систем и протекает без органической патологии желудочно-кишечного тракта и является функциональным нарушением $[1$, с. 8]. Функциональные нарушения в среднем сохраняются от 6 до 12 месяцев и носят благоприятный характер, по истечение данного времени могут переходить в органические заболевания. На примере СРК часто можно видеть трансформацию его в хронический колит [2, с. 102].

Цель работы: Определить этиологическую структуру синдрома раздраженного кишечника (СРК) в зависимости от возраста.

Материалы и методы: Обследовано 200 детей с различной гастроэнтерологической патологией в возрасте от 5 до 16 лет, посетивших амбулаторный прием у гастроэнтеролога. Дети были распределены на 2 возрастные группы: 5-12 лет - 102; 12-16 лет - 98 детей. Проведен анализ анамнеза, кал на патогенную микрофлору, определение маркеров ОКИ, кал на дисбактериоз, консультация психоневролога, при необходимости ФГДС, RRS, ЭЭГ.

Результаты: Результаты клинического обследования выявили, что на амбулаторном приеме дети распределялись по нозологическим формам следующим образом 25\% обострение хронического гастрита, $16 \%$ - хронический гастрит в стадии ремиссии, $31 \%$ - функциональные заболевания желудочно-кишечного тракта (дисфункция сфинктра Одди гастро-эзофагальный рефлюкс, дуодено-гастральный рефлюкс); $28 \%$ - СРК.

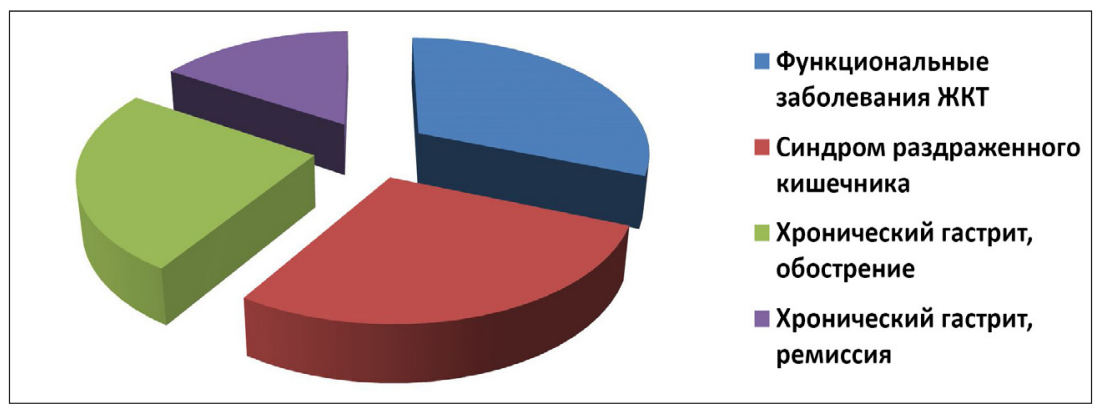

Рис. 1. Распределение детей по нозологическим заболеваниям на амбулаторном приеме гастроэнтеролога 
У 56 (28\%) обследованных детей был выявлен СРК. У 21(37\%) этот синдром возник после перенесенных стрессовых ситуаций: проблемы в семье, связанные с гиперопекой ребенка, самоутверждение на фоне пубертатного периода, асоциальным поведением родителей и других членов семьи, коллективе: связанные с лидерскими амбициями ребенка, подавлением и непониманием ребенка в классе и учителями, не желанием ребенка заниматься навязанными ему видами деятельности; экзамены; плохая успеваемость. 14 (66\%) детей этой группы были старше 12 лет. У 35 (63\%) детей диагносцирован СРК постинфекционной природы. Из них у 19 (34\%) была выявлена патогенная микрофлора: сальмонелла 9 (48\%), дизентерийная палочка 5 (26\%), патогенная кишечная палочка 5 (26\%).

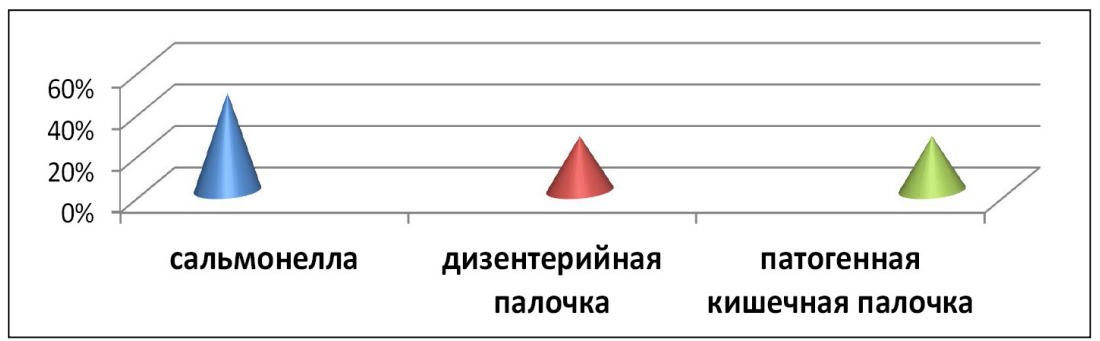

Рис. 2. Количественное распределение патогенной микрофлоры при постинфекционном синдроме раздраженного кишечника

У 16 (29\%) обследуемых детей был выявлен избыточный рост кишечной микрофлоры с наличием клебсиеллы 7 (43,8\%\%), золотистого стафилококка 4 (25\%\%), протея 3 (18,7\%\%), цитробактера 2 (12,5\%).

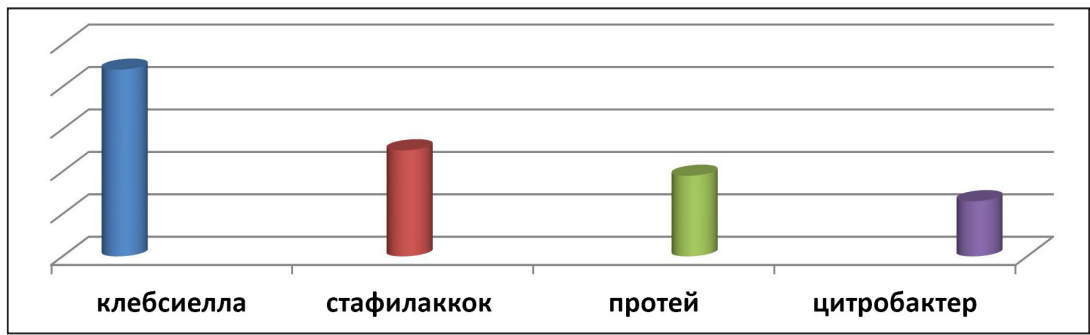

Рис. 3. Количественное распределение условно патогенной микрофлоры при постинфекционном синдроме раздраженного кишечника

Сочетание различных условно-патогенных возбудителей зарегистрировано у 70\% больных с СРК. Снижение бифидофлоры ниже нормы за- 
регистрировано у 21 (38\%), лактофлоры кишечника у 13 (24\%) больных с СРК.

Жалобы, предъявляемые детьми с СРК, имели отличия в зависимости от характеристики этого синдрома, так при психогеннообусловленном СРК боли в животе схватообразного характера отмечались у $20 \%$ больных; зависимость стула от приема пищи с последующим облегчением у $28 \%$; связь болей в животе с раздражающим агентом у $18 \%$; изменение стула: понос или запор у $20 \%$; головные боли, повышение давления в ответ на действие раздражающего фактора $14 \%$; сочетание симптомов зарегистрировано у $82 \%$ детей.

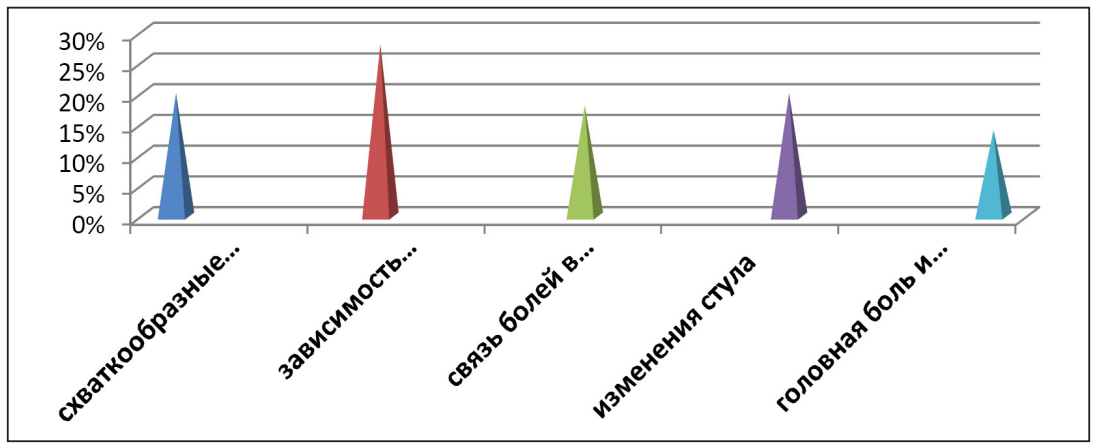

Рис. 4. Клинические симптомы психогеннообусловленного синдрома раздраженного кишечника

Клинические проявления постинфекционного СРК при наличии антигенов патогенной микрофлоры и наличии в крови антител к острой кишечной инфекции в низких титрах характеризовались болями в животе у $36 \%$ больных детей, ложными позывами на дефекацию (16\%), запорами $(16 \%)$, жидким с умеренным количеством слизи (16\%), субъфебрильной температурой (16\%). Сочетание клинических симптомов имело место у $71 \%$ детей с СРК (рис. 5). При наличии в кишечнике условно-патогенной микрофлоры постинфекционный СРК клинически характеризовался следующим образом: боли в животе ноющего характера у (19\%) детей этой группы, облегчение боли после акта дефекации (31\%), снижение массы тела более $7 \%$ от исходной (12\%), кожные высыпания по типу аллергической крапивницы (13\%), жидкий стул без примесей слизи 1-3 раза в сутки (25\%). И сочетание клинических симптомов имело место у $88 \%$ детей этой группы (рис. 6). 


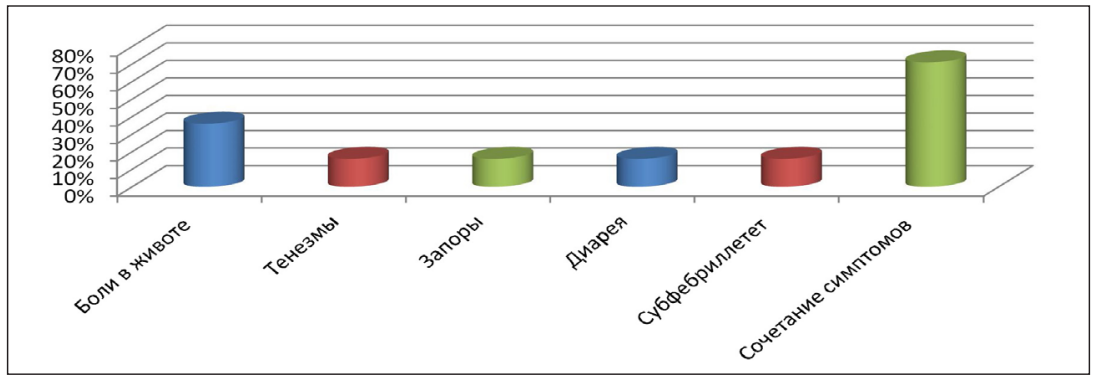

Рис. 5. Клинические проявления постинфекционного СРК при наличии патогенной микрофлоры.

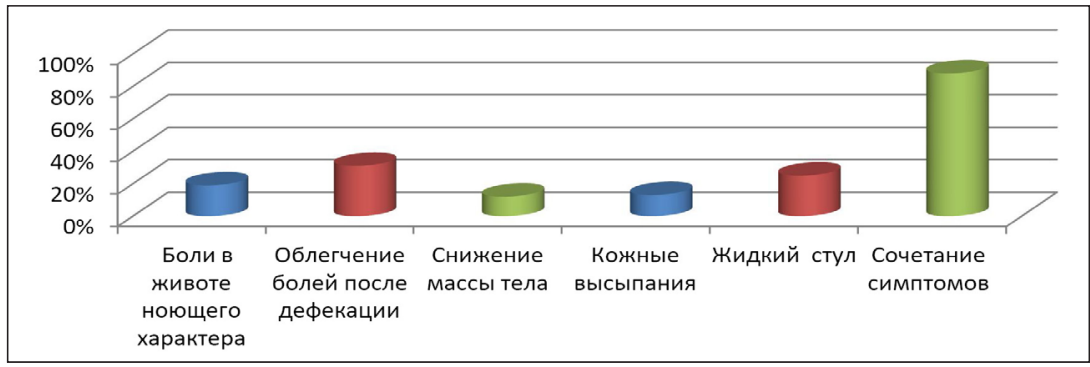

Рис. 6. Клинические проявления постинфекционного СРК при наличии условно-патогенной микрофлоры.

Дифференцированный подход к жалобам имеет большое значение для правильной постановки диагноза и выбора оптимальной схемы лечения.

\section{Выводы}

1. У детей от 5 до 12 лет СРК в основном носит постинфекционный характер и проявляется наличием как патогенной, так и условно-патогенной микрофлоры.

2.У детей старше 12 лет СРК является отражением стрессовых ситуаций и является психогеннообусловленным.

3. У всех больных детей с постинфекционным СРК имело место снижение как бифидо так и лактофлоры.

4. Клиническая картина СРК определяется видом этого синдрома.

5. Дифференцированный подход к клинике, обязательным и дополнительным методам обследования больного дает возможность выбора оптимальной терапии. 


\section{Список литературы}

1. Кучумова С.Ю. Патогенетическое и клиническое значение кишечной микрофлоры у больных с синдромом раздраженного кишечника: Дис. ... канд. мед. наук. М., 2016. 195 с.

2. Ивашкин В.Т., Маев И.В., Шептулин А.А. и др. Резолюция Экспертного совета «Как улучшить результаты лечения больных с функциональной диспепсией и синдромом раздраженного кишечника?» // Рос. журнал гастроэнтерологии, гепатологии, колопроктологии. 2016. № 2. С. 101-104.

\section{References}

1. Kuchumova S.Yu. Patogeneticheskoe i klinicheskoe znachenie kishechnoy mikroflory u bol'nykh s sindromom razdrazhennogo kishechnika [Pathogenetic and clinical violation of intestinal microflora in patients with irritable bowel syndrome]: Dis. ... kand. med. nauk. M., 2016. 195 p.

2. Ivashkin V.T., Maev I.V., Sheptulin A.A. et al. Ros. zhurnal gastroenterologii, gepatologii, koloproktologii. 2016. № 2, pp. 101-104.

\section{ДАННЫЕ ОБ АВТОРАХ}

Малеева Нина Петровна, к.м.н., доцент кафедры сестринского дела ФГБОУ ВО «Оренбургский государственный медииинский универcumem» $M 3$ РФ

ул. Советская, 6, г. Оренбург, 460001, Российская Федераиия ninamaleeva@list.ru

Кацова Галина Борисовна, к.м.н., доцент кафедры сестринского дела ФГБОУ ВО «Оренбургский государственный медииинский универcumem» $M 3$ РФ

ул. Советская, 6, г. Оренбург, 460001, Российская Федерация

\section{DATA ABOUT THE AUTHORS}

Maleeva Nina Petrovna, Ph.D., Associate Professor at the Department of Nursing Orenburg State Medical University, Ministry of Health of the Russian Federation

6, Sovetskaya str., Orenburg, 460001, Russian Federation ninamaleeva@list.ru

Katsova Galina Borisovna, Ph.D., Associate Professor at the Department of Nursing Orenburg State Medical University, Ministry of Health of the Russian Federation

6, Sovetskaya str., Orenburg, 460001, Russian Federation 